\title{
ESTUDOS SOBRE Ascia monuste orseis (GODART, 1818) (Lep., Pierididae)
}

\author{
LUIZ GONZAGA E. LORDELLO \\ (kiscola Superior de Agricultura "Luiz de Queiroz" da \\ Universidade de São Paulo) \\ RUBENS ALVES RODRIGUES \\ (Instituto Agronômico do Estado de São Paulo)
}

INDICE

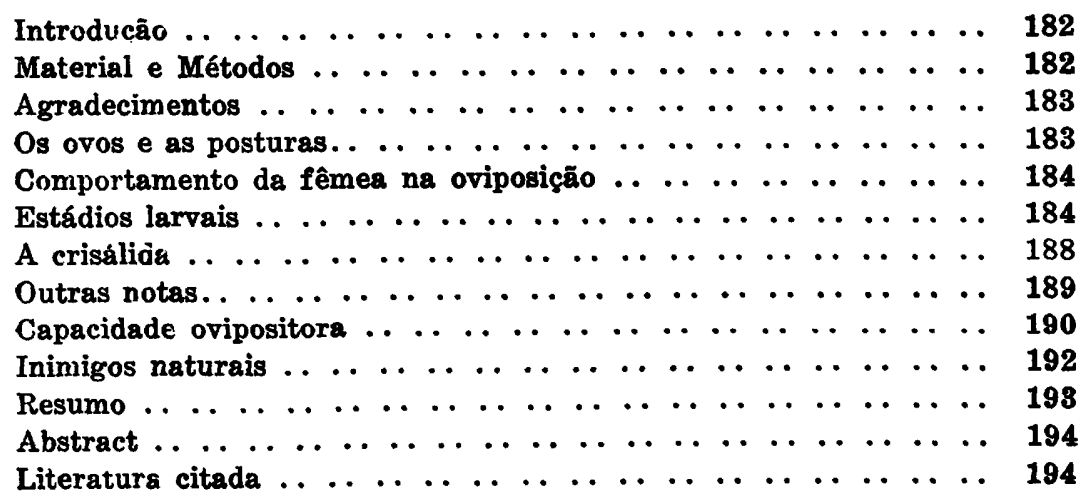




\section{INTRODUÇÃO}

Em Hirs de 1951, um de nós sugeriu a realização de um estudo biológico acêrca de Ascia monuste orseis (Godart, 1818), o conhecido Pierididae cujas lagartas, chamadas "coruquerê", constituem velho inimigo da couve e de outras Crucíferas cultivadas.

Embora conhecendo o estudo de D'ALMEIDA (1922), dado à lume em suas importantes "Mélanges Lépidoptérologiques", decidimos dar início às nossas observações, não só com o objetivo de recapitular a bionomia da espécie nestas regiōes do Estaco de Sáo Paulo (Piracicaba e Campinas), como de procurar registrar tatos que por ventura não tivessem sido referidos ou estudados por aquêle eminente entomólogo brasileiro.

Cumo praga que é de algumas Cruciferas de interêsse econimuco, $A$. $m$. orseis tem sido referida nas publicações de diversos pesquisaciores, sendo largamente distribuida no Brasil.

Para a couve, a espécie representa, a nosso ver, um inimigo bem menos importante que o "pulgão" (Brevicoryne brassicae (L.), Hom., Aphididae), uma vez que suas lagartas podem ser tácilmente combatidas nas culturas, pela catação manual.

\section{MATERIAL E MÉTODOS}

Estabelecido o nosso plano de trabalho, puzemo-nos a procura de pesturas do inseto ou de qualquer outro material, afim de iniciar as observações. A primeira postura data de 3 de dezembro de 1951. Até então, nada que se referisse ao Pierididae havia sido constatado, não só nas buscas efetuadas nas plantaçĩes do Instituto Agronômico de Campinas, como nas da Escola Superior de Agricultura "Luiz de Queiroz", em Piracicaba, bem ainda em culturas particulares.

Daquela data em diante, outras posturas e lotes de lagartas forám sendo coligidos.

As criações foram feitas sôbre fôlhas de couve (Brassica oleracea L., var. acephala D. C.), diáriamente renovadas; afim de estabelecermos os períodos da vida larvária, as lagartas foram separadas em caixas de Petri, com a quantidade de alimento suficiente para um dia. 


\section{AGRADECIMENTOS}

Agradecemos penhoradamente ao entomólogo Prof. Dr. Luis De Santis, da Universidade de La Plata (Rep. Argentina), pelo auxílio que nos prestou, identificando os parasitos do Lepidoritera $\mathrm{cm}$ estudo, obtidos durante as observações.

\section{OS OVOS E AS POSTURAS}

O número de ovos das posturas coligidas na natureza variou de 26: a 62. As fêmeas realizaram-nas, indiferentemente, na págira sup€rior ou inferior das fôlhas de couve. As descrições seguintes baseam-se em uma postura obtida em Campinas, em 3 de dezembro de 1951.

is nvis, em número de 20 , foram, neste caso, postos na face supericr de uma fôlha, próximos ao bordo, um em seguida ao outro, equidistantes entre si e formando fileiras mais ou menos paralelas, do que resultou a figura de um quadrilátero apresentada pela postura.

O óvo é alongado, afilando-se para as extremidades, principalmente para a distal. A extremidade basal adere fácilmente a qualquer objeto; com efeito, ao procurar mover um ôvo, sob a lupa, êle logo aderia á agulha, pelo seu extremo inferior, onde, aliás, pôde-se notar a presença de uma substância gelatinosa, responsável pelo fato.

O cório é ornado por 10 linhas longitudinais salientes, que dividem-no em lobos deprimidos os quais, por sua vez, são cortados por delicadas estrias transversais e equidistantes, visíveis sob a lupa

A superfície superior, levemente escavada, é tomada por uma depressão circular, rodeada por curtos lobos brancacentos, em númerci de 8 a 9.

A cór do ôvo é amarela, com brilho e com a extremidade superior clara e transparente.

Tal ccmo era de se esperar, quando se aproxima o momento da eclosão, os ovos se alteram, adquirindo tonalidades mais escuras. Estando prestes a eclodir, percebem-se, sob a lupa, os movijuentos em seu interior, da lagarta que se prepara para romper o corio. Os movimentos podem ser acompanhados não só pe!os dois pontos negros correspondentes às mandíbulas como, por transparência, pela observação dos pêlos da lagarta que, nessa ocasião, acham-se aplicados ao seu tegumento. 
Os ovos deformam-se pela pressão exercida pela larva em seu interior.

Afim de ganhar o meio externo, a lagartinha rompe o cório lateralmente, num ponto próximo da extremidade distal. $\mathrm{O}$ tempo áccorrente entre o início dos movimentos para ganhar o exterior aré c momento em que a lagarta sai do ôvo, em várias observaçōes, foi de 35 até 60 minutos.

O cório dos ovos eclodidos constitui o primeiro alimento das lagarias. No limbo, permanecem pequenas zonas circulares escuras, marcando os pontos onde os ovos foram depositados.

As dimernsões encontradas para o ôvo foram : $1,25 \mathrm{~mm}$ de complimento e $0,5 \mathrm{~mm}$ de largura em sua porção média.

\section{COMPORTAMENTO DA FÊMEA NA OVIPOSIÇÃO} fîmea.

'Tivemos oportunidade de observar a oviposição de uma

Eila esvoaçou ao redor das plantas por um tempo mais ou menns longo. Finalmente, pousou sôbre a fôlha escolhida, nas proximidades dos bordos, e iniciou a postura. O tempo decorrente entre a expulsão de dois ovos consecutivos andou por volta de 5 segundos.

Depositado um ôvo, o seguinte foi pôsto ao lado do primeiro, e, assim, até completar-se uma primeira fileira, perpendicular ao eixo do corpo. Então, a borboleta passou a depositá-los numa filcira adeante e paralela à anterior. Dessa forma, ao concluir a oviposição, isto é, ao expulsar os ovos que constituiram a fiieira final, a fêmea se apresentava com o abdômen francarnente recurvado para a frente de seu corpo. Para depositar os últimos cvos, ela viu-se por vezes obrigada a deslocar as patas anteriores, afim de pô-los nos pontos, em que estas tocavam no limbo.

Do comportamento da borboleta durante a postura resultou - agi upamento de ovos a que já nos referimos, constituindo uma f́jgura com a forma aproximada de um quadrilátero.

Terminado o trabalho da oviposição, a borboleta se apresentava de tal forma extenuada que pôde ser fácilmente capturada.

\section{ESTADIOS LARVAIS}

$1^{\circ}$. Essiádio - Ao nascer, com $3 \mathrm{~mm}$ de comprimento, a lagarta c anarelo-pálida uniforme, com brilho. A cabeça ostenta coloração mais intensa. Algum tempo após, a lagarta adquire 
tons esverdeados, principalmente nos primeiros segmentos do corpc.

A cabeça é grande, ornada por pêlos claros, bem destacada do cor po, do qual se separa por uma linha estreita e escura; sutura cefálicá mais ou menos bem distinta.

'Todos os segmentos do corpo mostram pêlos curtos e negros, implantados em elevações que aos poucos vão escurecendo e, consequentemente, tornando-se mais distintas.

O protórax e todos os segmentos do abdômen mostram, vistos de cima, cada um, 6 verrugas de implantação dos pêlos. Numa prirreira linha, na porção anterior do segmento, situam-se 4 dessas verrugas, duas das quais, as externas, podem ser tidas como marcando os limites da área dorsal. Entre elas estão as outras duas da primeira linha, maiores e localizadas um pouco adiante. $\mathrm{Na}$ segunda linha estão os dois pêlos que perfazem o total de 6 por segmento, cujas verrugas são bem menores que as dos 4 referidos.

O meso e o metatórax apresentam apenas a primeira fileira de 4 pêlos anteriores, faltando os outros dois.

Dcs pelos claros laterais, uns se destacam, por serem mais longcs, parecendo não faltar em nenhum dos segmentos.

Os estigmas são, neste estádio, pouco visíveis e salientes na superijcie do corpo; logo abaixo da linha dos estigmas, localizam-se os pêlos claros e mais longos, há pouco referidos.

Tôdas ás patas são claras; apenas as torácicas apresentamse cum a extremidade distal escurecida. Pubescência clara aparece crnamentando tôdas as patas (torácicas e membranosas).

As lagartinhas estão contínuamente elaborando fios sedosos e clarcs, o que dificulta o trabalho de passá-las de uma para outra têlha, por aderirem ao pincel empregado para tal. A parte do limbo onde elas se aglomeram apresenta-se tomado por um emaranhado dêsses fios.

No finai dêste primeiro ínstar, as lagartas apresentam-se diferentes. $D \epsilon$ fato, passam a exibir a área dorsal verde-clara, mais culorida na porção anterior do corpo. Em alguns pontos, pode-se perce $\epsilon$ ber tons azulados.

A race inferior também se mostra verdoenga e, em cada la'o do corpo, aparece uma faixa amarelo-esverdeada limitante com a área dorsal. O restante das faces laterais é de um colorido semelhante ao do dorso, o qual continua-se pelo ventre. As verrugas de implantação dos pêlos destacam-se no fundo verde.

A cabeça continua amarelada, com a pubescência clara já refericiá. 
ivesta idade, as lagartinhas, agora com cêrca de $4,5 \mathrm{~mm}$ de compr:mento, roem o parênquima foliar, chegando a abrir orifícios no limbo.

Na ecdise, a primeira parte a ser abandonada pela lagarta é a cápsula cefálica que, em muitos casos, permanece prêsa ao animal, nos seus primeiros segmentos, não caindo ao solo. As peles são frequentemente aproveitadas como alimento.

2". Estáadio - São sensíveis as modificações sofridas pelas lagartas. ao entrar nesta nova fase de sua evolução. A cabeça mostra-se amarelo-pardacenta, mais ou menos brilhante, tendo escurecido sensívelmente. Percebem-se agora, nítidamente, as verrugas de implantação dos longos pêlos brancos cefálicos, pois, pela sua coloração ferrugínea, destacam-se no fundo amareladc. A sutura cefálica é mais ou menos evidente; os ramos em que se bifurca deixam ver, atraz de si, uma sombra pardoescura As faces laterais e a frente da cabeça mostram-se com mancias ferrugíneas.

A tonalidade verde da área dorsal é agora mais intensa, continuancio a ser mais colorida a parte anterior do corpo. As verrugás são pardo-escuras na metade terminal do corpo e franca:nente negras na extremidade anterior.

As faixas supraespiraculares são pardo-ferrugíneas, havendo, pois, escurecido bastante. $O$ restante da face lateral do corpo, bem ccmo o ventre, é amarelo-esverdeado, sendo que a metade anterior ventral é também mais colorida que a posterior.

As patas verdadeiras são, nesta idade, negras retintas em sua porção terminal. As pernas membranosas ostentam coloração verde-amarelada, com brilho.

Os pèlos claros laterais curvaram-se para traz, não se apresentando retos como antes. Nascem de elevações marrom-escuras, acima das quais estão os estigmas.

A linha escura que separa a cabeça do restante do corpo já nâo é tão distinta.

Observada a ôlho nú, as lagartinhas, com $5 \mathrm{~mm}$ de comprimento, mostram-se esverdeadas, mais escuras na parte anterior, com riscas negras correspondentes às verrugas de implantação dos pêlos, que se sucedem e se confundem, dando-nos o aspecto de uma linha contínua. Além dêsses pêlos negros, nascidos das verrugas a que temos nos reportado, as lagartas mostram outros, curtos e claros (verdadeira pubescência), distribuidos indiferentemente nos lados do corpo e nas patas membranosas e torácicas.

No final da segunda idade, a lagarta atinge até $10 \mathrm{~mm}$, conservando-se mais ou menos com os mesmos característicos. 
3. E'stádio - A lagarta, nesta idade, é muito mais provida de pêlos que nas anteriores. Com efeito, tôdas as formações pilosas desenvolvem-se, tornando-se mais longas. A cabeça continua de côr amarelo-esverdeada, com o colar que a separa do corpo bastante fino, com máculas negras frontais e os tubérculos de onde nascem os pêlos.

A área dorsal mostra-se de um verc̈e ainda mais intenso que no estádio precedente, com as verrugas dos pêlos negras retintas.

O pronoto é práticamente todo preto, apenas atravessado pela linha mediana, de côr verde-brancacenta, que se evidenciou nesta idade.

As patas abdominais deixam ver uma mancha escura não muito nítida em sua face externa. A faixa supraespiracular é, agora, cinza-escura, com tons roxos e a face ventral, esverdeada, exibe matizes pardos.

Fercorrendo o dorso, diferenciou-se, como dissemos, uma risca verdoenga, que é delimitada pelas verrugas de implantação dos pêlos do dorso e por pequenas máculas escuras, nos pontos onde faltam as verrugas.

O comprimento, no final do $3^{\circ}$. ínstar, é de $15 \mathrm{~mm}$.

$4^{\circ}$. Estádio - A coloração geral mantém-se a mesma. Os pêlos, principalmente aquêles claros laterais cresceram ainda mais.

Ao terminar a idade, as lagartas medem cêrca de $20 \mathrm{~mm}$.

50. Estádio - A coloração da faixa que abrange os estigmas, até agora verde-amarelada, torna-se, nesta última fase da vida larvária, francamente amarela, na qual os espiráculos aparecem pretos e elípticos. Abaixo dessa área espiracular, para o ventre, a coloração se conserva verdoenga, com máculas pardas.

A. fita supraespiracular continua cinza, com tons roxos. A ôlho nú, pode ser definida como simplesmente escura, tendendo ao negro.

A área dorsal pode ser dita como tomada por cinco faixas: um par marginal, de côr amarelo-clara, esverdeada; uma fita única, mediana, de igual côr, e duas outras, situadas entre a fita impar e a faixa limitante referida, de coloração cinza, com tons roxos, tal como a área supraespiracular.

Nas faces externas das patas membranosas, são bem distinias as pequenas elevações escuras, de onde nascem os pêlos claros. 
O pronoto apresenta-se, tal como desde a terceira idade, tomado por duas áreas negras, resultantes do fato de se terem confundjdas, nesse segmento, as saliências de implantação dos pêlos dorsais. Essas áreas negras são, como já dissemos, separadas pela risca que percorre o dorso.

Ac terminar o estádio, as lagartas atingem até $35 \mathrm{~mm}$, havenđo algumas cujo comprimento não alcança $30 \mathrm{~mm}$. De fato, os lotes nascidos de uma mesma postura não são uniformes em seu desenvolvimento.

A voracidade das lagartas torna-se máxima neste estádio final. Doze delas, colocadas em uma caixa de Petri, devoraram, em 24 horas, uma fôlha de couve de aproximadamente $15 \mathrm{~cm}$ de comprimento e 10 de largura, inclusive o peciolo.

\section{A CRISALIDA}

Chegado o momento de sofrerem a ninfose, as lagartas suspendem a alimentação e, em cativeiro, migram para as partes altas do insetário, onde se fixam afim de passar pela transformação.

As crisálidas mediram 25 a $27 \mathrm{~mm}$ de comprimento e 6 a $7 \mathrm{~mm}$ de largura, ao meio do corpo. A coloração geral é amarelada, algumas crisálidas exibindo tons rosados leves. $O$ dorso é crnadic por numerosos pontos negros; a face ventral também mostra pontos escuros, em bem pequeno número.

Há uma carena percorrendo o dorso do abdômen a qual, aliás, pouco se destaca do corpo. As duas raias longitudinais amarelas referidas por D'ALMEIDA (1922), uma de cada lado da carena abdominal, apresentaram-se bem pouco nítidas em nossos exemplares.

No dorso aparecem dois espinhos negros, um de cada lado, cujas bases de implantação são ornadas por pequenas máculas pretas, diferentemente desenvolvidas nos vários exemplares. $O$ tórax possui uma protuberância, manchada mais ou menos de escurc em sua parte alta. A cabeça apresenta-se igualmente manchada, com saliências e curtos pêlos claros, visíveis sob a lupa

A região das asas é clara, com uma mancha alongada escura em seu bordo dorsal e curto risco negro na parte média do bordo ventral.

A. face ventral é práticamente imaculada, pois mostra bem poucos pontos negros no abdômen, deixando ver, quando se tem a crisálida deitada sôbre o dorso, os dois riscos do bordo ventral do estojo das asas. 
A crisálida é succinta, isto é, prende-se ao local escolhido não só pelo cremaster como por uma cinta de fios em torno do meio do corpo o que, aliás, constitui característico dos membros da família a que a espécie pertence.

A cinta que circunda o corpo é de fato resistente, não se rompendo pelos enérgicos movimentos das crisálidas, principalmente quando recentemente formadas.

Com respeito à duração dos diversos estádios evolutivos, fornecemos as anotações referentes a 10 lagartas obtidas de postura coletada em Campinas, em 2 de janeiro de 1952.

Colheita dos ovos

Eclosão

$1^{2}$. Ecdise

$2^{2}$. Ecdise

$3^{2}$. Ecdise

$4^{2}$. Ecdise

Crisalidação

Nascimento dos adultos
2-I-1952

3-I-1952

$5-\mathrm{I}-1952$

7-I-1952

8-I-1952

10-I-1952

13 e 14-I-1952

20-I-1952

As datas indicadas permitem-nos estabelecer os tempos de-

corridos nos vários períodos do desenvolvimento (temperatura média $=22^{\circ} \mathrm{C}$ ).

Incubação
$1^{2}$. Idade
$2^{2}$. Idade
$3^{2}$. Idade
$4^{2}$. Idade
$5^{2}$. Idade
Crisálida

Coriforme pudemos verificar posteriormente, a incubação dos ovos exigiu cêrca de 4 dias.

\section{OUTRAS NOTAS}

Suspendemos a alimentação de um lote de 14 lagartas, assim que ingressaram para o último estádio, visando a crisalidação prematura.

Uma parte das lagartas se metamorfoseou, outra sucumbiu. Das crisálidas obtidas, umas foram devoradas pelas lagartas 
ainda ativas. Os poucos adultos mediram apenas 45 a $55 \mathrm{~mm}$ de envergadura, a maior parte dos quais emergiu das crisálidas em precárias condições.

\section{CAPACIDADE OVIPOSITORA}

Os adultos obtidos em laboratório foram separados, aos casais, em mangas de vidro, onde se manteve não só fôlhas de couve diáriamente renovadas, como uma mecha de algodão embebida de uma mistura de água e mel.

A nossa preocupação consistia em conhecer a capacidade ovipositora aproximada das fêmeas, muito embora em condições bastante artificiais.

Dos diversos casais separados, em apenas três obtivemos êxito, isto é, sòmente êstes realizaram posturas em cativeiro, sendo que em um único foi verificada a cópula. Os números de ovos obtidos foram, respectivamente, de 14, 92 e 202.

Nos três casos, os ovos foram postos sôbre qualquer das faces da fôlha e também nas paredes internas da manga de vidro.

Eis o que pudemos registrar com respeito aos casais mencionados :

$1^{\circ}$.) Nascimento dos adultos

$1-\mathrm{I}-1952$

$1^{2}$. oviposição, com 10 ovos

$3-\mathrm{I}-1952$

$2^{\text {a }}$. oviposição, com 4 ovos

4-I-1952

Total

14 ovos

Us adultos morreram em 7 (fêmea) e 8-I-1952 (macho). Todos os ovos eram inférteis.

$2^{\circ}$.) Nascimento dos adultos

$1^{2}$. oviposição, com 2 ovos

$2^{2}$. oviposição, com 32 ovos

$3^{2}$. oviposição, com 35 ovos

$4^{2}$. oviposição, com 23 ovos

Total

92 ovos

$30-$ XII-1951

$1-\mathrm{I}-1952$

2-I-1952

4-I-1952

6-I-1952

$O$ adulto macho morreu em 5-I-1952 e a fêmea em 8-I-1952, sendi) que todos os ovos não lograram eclosão. 
$3^{\circ}$.) Nascimento dos adultos

$1^{2}$. oviposição, com 12 ovos

$2^{2}$. oviposição, com 48 ovos

$3^{2}$. oviposição, com 73 ovos

$4^{2}$. oviposição, com 69 ovos

Total

202 ovos
31-XII-1951

$1-\mathrm{I}-1952$

2-I-1952

4-I-1952

$6-\mathrm{I}-1952$

Macho e fêmea morreram em 7-I-1952.

Neste último casal foi observada a cópula, que se iniciou por volta das 14 horas do dia 3-I-1952, tendo sido relativamente prolongada, pois os dois sexos permaneceram unidos até cêrca das 17 horas.

Dos ovos férteis, obtivemos um bom lote de lagartas, cuja evolução também foi acompanhada.

A seguir, resumimos o protocolo de 10 lagartas nascidas dos ovis de 4-I-1952 (temperatura ao redor de $22^{\circ} \mathrm{C}$ ).

Postura

Eclosão

$1^{2}$. Ecdise

2. Ecdise

$3^{n}$. Ecdise

$4^{2}$. Ecdise

Crisalidação

Emergência dos imagos
4-I-1952

8-I-1952

$10-\mathrm{I}-1952$

11 e $12-\mathrm{I}-1952$

$13-\mathrm{I}-1952$

15 e $16-\mathrm{I}-1952$

20-I-1952

26-I-1952

Dessas datas, depreende-se que as diversas fases do ciclo tiverám a duração seguinte :

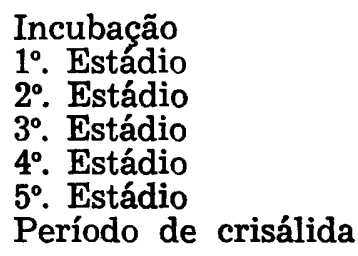

4 dias

2 dias

1 a 2 dias

1 a 2 dias

2 dias

5 a 6 dias

6 dias

Os adultos, em cativeiro, viveram de 5 a 9 dias, em presença ou ausência da mecha embebida em água e mel, parecendonos que tal fornecimento não teve nenhuma influência sôbre a longevidade.

A oviposição iniciou-se 1 a 2 dias após o nascimento. 


\section{INIMIGOS NATURAIS}

Uma de nossas preocupações foi conhecer os inimigos naiurais da espécie, nas regiōes de nossas observações. Concluimus que $A$. m. orseis é muito pouco controlada por inimigos naturajs

Nenhum parasita dos ovos foi assinalado.

Procurando obter crisálidas atacadas, transferimos para pés de couve das plantações do Instituto Agronômico, lotes de lagartas adultas nascidas no laboratório. As crisálidas localizadas, provenientes dos lotes levados ao campo, foram postas em caixas de Petri, afim de reter os possíveis parasitos. Por outro lado, também coletamos outras crisálidas e lagartas a termo, com à mesma finalidade.

Obtivemos emergência de vespinhas sòmente de uma crisálida, da qual sairam diversos exemplares de Pteromalus caridei Brèthes, 1913 (Chalcidoidea, Pteromalidae), parasitismo que, segundo nos parece, é aqui assinalado pela primeira vez.

A coleção da Secção de Entomologia Aplicada do Instituto Agronômico possui alguns exemplares de Apanteles glomeratus (L., 1758) (Ichneumonoidea, Braconidae), obtidos de lagartas coletadas em Campinas em maio de 1948.

Nãc conseguimos, durante o nosso trabalho, nenhum caso de infestação de lagartas pelo Braconidae mencionado, parasitismo, aliás, já registrado por SAUER (1946) e COSTA LIMA (1948). Também nenhum dos Chalcididae (Brachymeria comitatador (Walker, 1861) e B. ovata (Say, 1824)) referidos por êste Autor, foram assinalados.

Alguns cultivadores de plantas olerícolas nos informaram que o "pardal" (Passer domesticus domesticus (L.)), o conhecido Ploceidae europeu introduzido há anos no Brasil, pode alimentar-se não só das lagartas de $A$. $m$. orseis, como também do pulgão (Brevicoryne brassicae (L.)), que tanto prejudica as mesmas plantas nas quais as lagartas se criam.

De fato, o pardal possui hábitos insetívoros, confirmados pelo exame do conteúdo do papo de espécimes abatidos. As investigações de KALMBACH (1940), realizadas nesse sentido, são bastante interessantes. Entre os insetos capturados pelos pardais, principalmente quando ocupados com a nutrição dos filhotes, figuram não só larvas como adultos de Lepidoptera.

Diante dêsses conhecimentos, decidimos procurar verificar a afirmação dos olericultores. As nossas observações não per- 
mitiram esclarecer o assunto, sendo, contudo, de molde a negar a ação do Ploceidae como inimigo das lagartas de $A$. m. orseis. Com efeito, fôlhas de couve com lagartas foram colocadas em locais frequentados pelos pássaros. Estes foram vistos ao redor das fólhas, mas as lagartas permaneceram intactas.

\section{RESUMO}

A bjologia de Ascia monuste orseis (Godart, 1818) (Lep., Pierididae) foi estudada. O material utilizado foi coligido em Campinas e Piracicaba (Estado de São Paulo), durante os meses de dezembro de 1951 e janeiro de 1952 e constituiu-se principalmente de posturas do inseto.

O número máximo de ovos, obtido de uma fêmea, em condições de laboratório, foi de 202, sendo registradas algumas observações sôbre o comportamento da borboleta durante a oviposição na natureza.

Os ovos e as posturas são descritos. A incubação exigiu cêrca de 4 dias.

Durante a vida larvária, a espécie passa por 5 estádios, sofrendo, portanto, 4 ecdises. São descritas as lagartas em tôdas essas idades.

$\mathrm{O}$ ciclo completo, de ôvo a imago, andou ao redor de 22 dias. O $5^{\circ}$. estádio larval mostrou-se, de todos, o mais longo, consumindo 3 até 6 dias. $O$ período de crisálida abrangeu 6 a 7 dias.

Os adultos viveram, em insetário, 5 a 9 dias, quer em presença ou em ausência de uma mecha de algodão hidrófilo embebida de uma mistura de água e mel.

Unicamente um caso de parasitismo foi verificado, os Autores concluindo que, nestas regiões de São Paulo, na época em que as observações foram feitas, a espécie é muito pouco perseguida por agentes naturais de contrôle. $O$ parasito foi identificado pelo Professor Luis De Santis, da Universidade de La Plata (Rep. Argentina), como Pteromalus caridei Brèthes, 1913, interessante Hymenoptera da família Pteromalidae.

Os Autores procuraram esclarecer a ação do pardal - Passer domesticus domesticus (L.) - com relação às lagartas de A. $m$. orseis, uma vez que há, entre olericultores, a crença de que o referido Ploceidae constitui inimigo do Lepidoptera em estudo. As observações colhidas não permitiram uma conclusão, sendo, contudo, de molde a negar a ação do pássaro como devorador das lagartas. 


\section{ABSTRACT}

This paper includes a study of the biology of Ascia monuste orseis (Godart, 1818) (Lep., Pierididae) which was carried out in Campinas and Piracicaba (State of São Paulo, Brasil), during the months of december (1951) and january (1952).

References to the eggs and the posture, the behaviour of the female during the oviposition, the larval stages, the chrysalid, the capacity of oviposition of the female and the natural enemies of the species have been made.

\section{LITERATURA CITADA}

COSTA LIMA, A. da, 1948 - Entomófagos Sul Americanos (Parasitos $€$ Predadores) de Insetos Nocivos à Agricultura. Bol. Soc. Bras. Agron. (Rio de Janeiro), 11 (1): 1-82.

D'ALMEIDA, R. Ferreira, 1922 - Mélanges Lépidoptérologiques (Etudes sur les Lépidoptères du Brésil), 208 pp. Berlim.

KALMBACH, E. R., 1940 - Economic Status of the English Sparrow in the United States. Tech. Bull. of the U: S. Dep. of Agric.. 711: 1-66, fig. 1-7, est. 1-3.

SAUER, H. F. G., 1946 - Constatação de Himenópteros e Dípteros Entomófagos no Estado de São Paulo. Bol. Fitos. (Rio de Janeiro), 3 (1) : 7-23. 

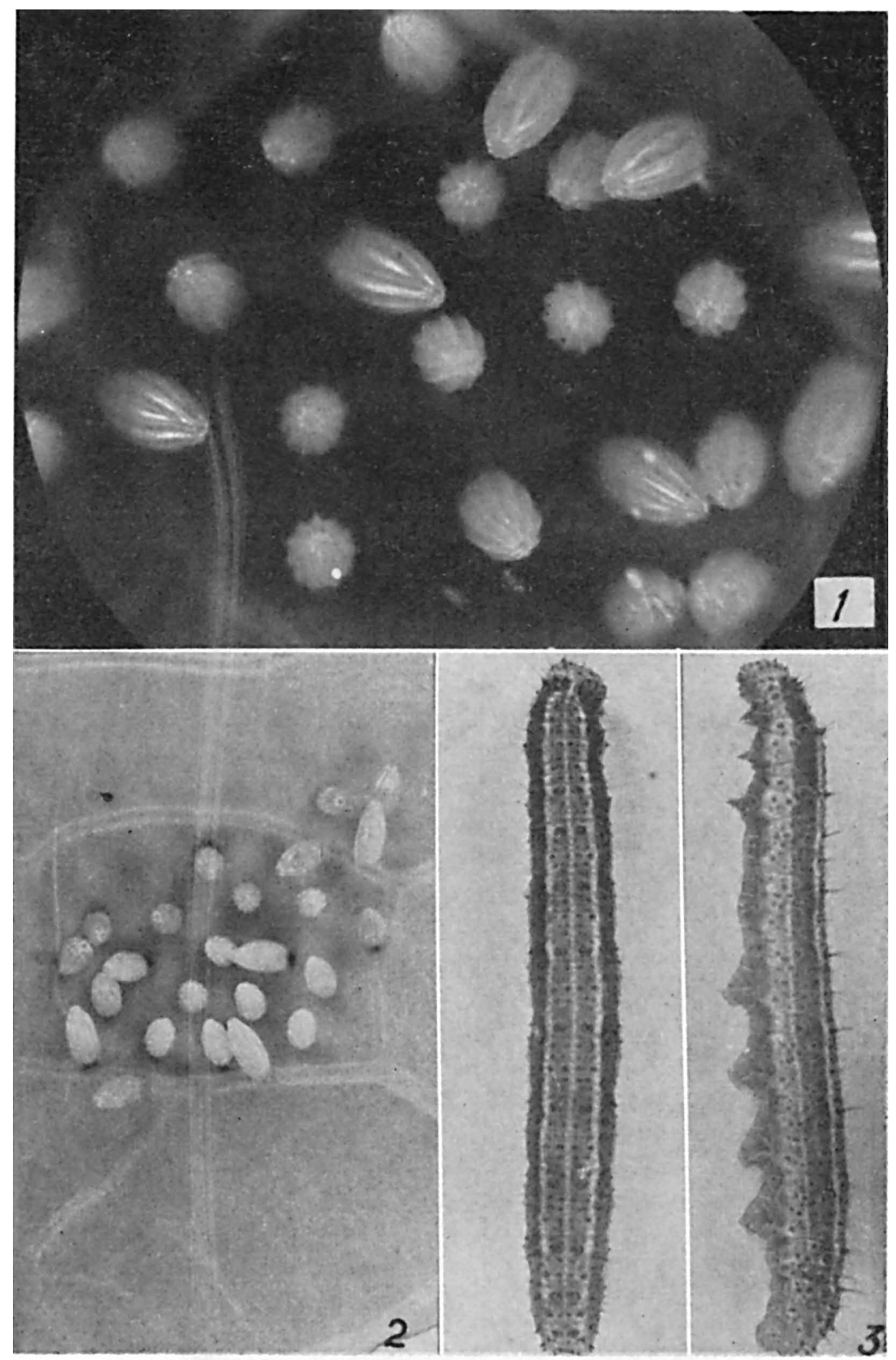

Ascia monuste orseis (Godart, 1818)

1 e 2) Ovos, em grande e pequeno aumento.

3) Lagartas adultas. 




Ascia monuste orseis (Godart, 1818)

4) Crisálidas fixas ao fôrro do insetário.

5) Crisálida, vista lateral.

6) Adulto macho.

7) Adulto fêmea. 